\title{
ROBUST CONTROLLERS FOR VARIABLE RELUCTANCE MOTORS
}

\author{
MOHAMED ZRIBI AND MUTHANA T. ALRIFAI
}

Received 12 June 2004 and in revised form 29 September 2004

This paper investigates the control problem of variable reluctance motors (VRMs). VRMs are highly nonlinear motors; a model that takes magnetic saturation into account is adopted in this work. Two robust control schemes are developed for the speed control of a variable reluctance motor. The first control scheme guarantees the uniform ultimate boundedness of the closed loop system. The second control scheme guarantees the exponential stability of the closed loop system. Simulation results of the proposed controllers are presented to illustrate the theoretical developments. The simulations indicate that the proposed controllers work well, and they are robust to changes in the parameters of the motor and to changes in the load.

\section{Introduction}

The variable reluctance motor is a synchronous motor which is comprised of iron laminations on the stator and rotor and copper phase windings on the stator. Torque is produced by the attraction of the closet rotor poles to the excited poles. In motoring operations, phase excitation is synchronized to rotor position such that the rotor poles are pulled toward the excited stator poles in the direction of rotation. In generating operations, phase excitation is synchronized to rotor position such that the rotor poles are pulled backward toward the excited stator poles in the direction opposite to the rotation.

Variable reluctance motors are almost maintenance free since they do not have mechanical brushes. Also, VRMs are not expensive because they do not have rotor windings or magnets. Moreover, VRMs can produce high torques at low speeds. These characteristics combined with the advancement in power electronics, and the availability of highspeed processors make variable reluctance motors attractive for many general-purpose industrial applications.

However, the variable reluctance motor is characterized by its inherent nonlinearities. Both spatial and magnetic nonlinearities are found in the VRM. Thus, nonlinear control techniques are needed to compensate for the nonlinearities of the motor.

Many nonlinear control techniques have been developed for the control of VRMs; the reader is referred to $[1,2,3,4,5,6,8,9,10,11,12,13,14,15,16,17,18,19,21,22,23,24$, 


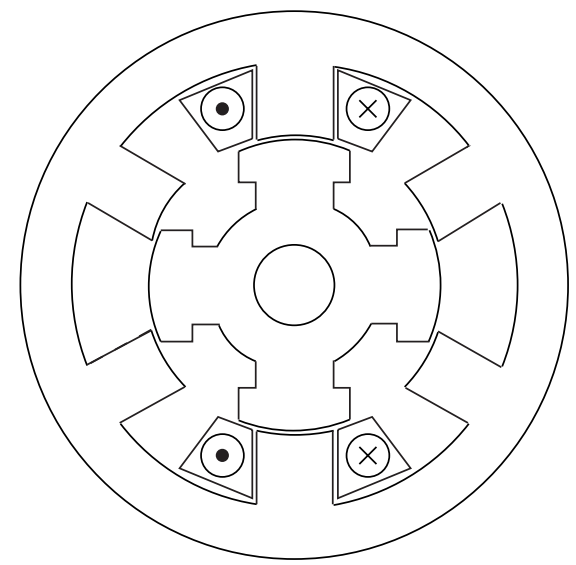

Figure 2.1. A 3-phase, 6/4 VRM. One-phase winding is shown.

$25,26,27,28,29,30]$ and the reference therein for an excellent overview of the different control schemes which have been developed for VRMs. Specifically, control techniques such as feedback linearization [13, 22], variable structure control [6], adaptive control $[16,19]$, optimal control [10], neural control [10], fuzzy control $[3,9,11]$, backstepping control [1] have been used for position and speed control of the variable reluctance motor. This paper uses robust nonlinear control techniques to control the speed of the VRM. The need of robust controllers for VRMs is motivated by the inherent nonlinearities of the motor and by the fact that some of the parameters of the motor are not to be known accurately.

The rest of the paper is organized as follows. Section 2 contains a brief overview on variable reluctance motors as well as the dynamic model of the motor. Sections 3 and 4 deal with the design of two controllers for the VRM. The simulation results of the proposed control schemes are presented and discussed in Section 5. Finally the conclusion is given in Section 6.

In the sequel, we denote by $W^{T}$ the transpose of a matrix or a vector $W$. We use $W>0$ $(W<0)$ to denote a positive (negative) definite matrix $W$. Sometimes, the arguments of a function will be omitted in the analysis when no confusion may arise.

\section{Dynamic model of the variable reluctance motor}

For any control system design, the development of a reliable mathematical model is essential for proper evaluation of the system's performance and for testing the effectiveness of the developed control schemes. For VRMs, both spatial and magnetic nonlinearities are inherent characteristics of the motor; a model which takes these nonlinearities into account needs to be considered for design purposes. The model suggested in [27] which takes magnetic saturation into account is adopted in this work. A $20 \mathrm{~kW}, 3$-phase VRM, which is documented in [27], is used for simulation purposes. The motor has six stator poles and four rotor poles, see Figure 2.1. 


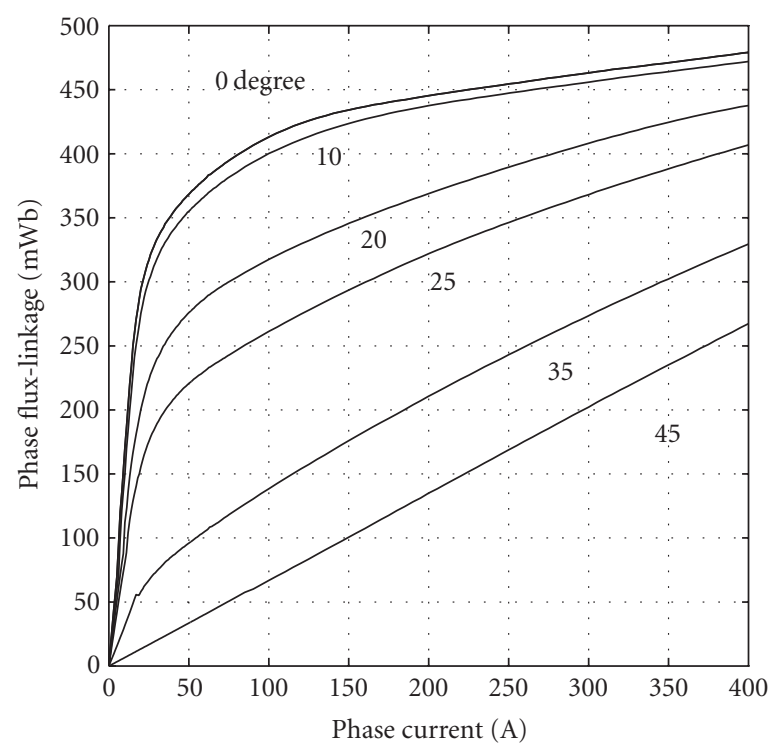

Figure 2.2. The magnetization characteristics of one phase of a 6/4 VRM.

The general voltage equation of an $m$-phase VRM can be written as

$$
v_{j}=R_{j} i_{j}+\frac{d \lambda_{j}}{d t} \quad(j=1,2, \ldots, m)
$$

where $v_{j}(j=1,2, \ldots, m)$ is the voltage applied to the terminals of the $j$ th phase, $R_{j}$ is the phase resistance, $i_{j}(j=1,2, \ldots, m)$ is the current associated with phase $j$, and $\lambda_{j}(j=$ $1,2, \ldots, m)$ is the flux linkage of the $j$ th phase.

The flux linkage $\lambda_{j}$ is a nonlinear function of both the phase current $i_{j}$ and the rotor position $\theta$, see Figure 2.2. The nonlinearities of $\lambda_{j}$ are due to the magnetic saturation and to the periodicity of alignment between the stator and the rotor poles. The flux linkage is defined as [27]

$$
\lambda\left(i_{j}, \theta\right)=a_{1 j}(\theta)\left[1-\exp \left(a_{2 j}(\theta) i_{j}\right)\right]+a_{3 j}(\theta) i_{j}, \quad i_{j} \geq 0(j=1,2, \ldots, m) .
$$

The coefficients $a_{1 j}, a_{2 j}$, and $a_{3 j}(j=1,2, \ldots, m)$ are periodic functions of the rotor position, and they can be expressed as truncated Fourier cosine series such that

$$
a_{k}=\sum_{r=0}^{n} A_{k r} \cos (\delta \theta r) \quad(k=1,2,3)
$$

where $\delta$ is the number of electrical cycles in each mechanical revolution. The parameter $A_{k r}$ represents the $r$ th Fourier coefficient of the $k$ th fitting coefficient. The Fourier coefficients of the VRM are determined by using the Marquardt gradient expansion algorithm [2]. 
The torque for phase $j, T_{e j}(j=1,2, \ldots, m)$, produced by a VRM with independent phases during both saturated and unsaturated magnetic operations, can be determined by using coenergy analysis [15] as

$$
T_{e j}=\frac{\partial}{\partial \theta} \int_{0}^{i_{j}} \lambda\left(i^{\prime}, \theta\right) d i^{\prime} \quad(j=1,2, \ldots, m) .
$$

The sum $T_{e}=\sum_{j=1}^{m} T_{e j}$ of the individual-phase torques gives the total torque.

Therefore, the complete dynamic model of the variable reluctance motor can be written as

$$
\begin{gathered}
\frac{d \theta}{d t}=\omega, \\
\frac{d \omega}{d t}=\frac{1}{J}\left\{T_{e}-T_{L}-D \omega\right\} \\
\frac{d i_{j}}{d t}=\left(\frac{\partial \lambda_{j}}{\partial i_{j}}\right)^{-1}\left\{-R_{j} i_{j}-\frac{\partial \lambda_{j}}{\partial \theta} \omega+v_{j}\right\} \quad(j=1,2, \ldots, m),
\end{gathered}
$$

where

(i) $\theta$ is the rotor position;

(ii) $\omega$ is the rotor speed;

(iii) $i_{j}$ is the current associated with phase $j$;

(iv) $\lambda_{j}$ is the flux linkage of the $j$ th phase;

(v) $v_{j}$ is the control voltage of the $j$ th phase;

(vi) $T_{e}$ is the total electromagnetic torque;

(vii) $T_{L}$ is the load torque;

(viii) $J$ is the rotor inertia;

(ix) $D$ is the damping factor;

(x) $R_{j}$ is the $j$ th phase resistance.

The output of the system can be taken as the rotor position $\theta$ or the rotor speed $\omega$, whereas $v_{j}$ acts as the control input of the $j$ th phase. This paper deals with speed control, thus the output of the VRM system is $y=\omega$.

Remark 2.1. An electronic commutator determines which phase to be excited at any given instant of time. The inputs to the electronic commutator are the turn-on angle $\theta_{\text {on }}$, the turn-off angle $\theta_{\text {off }}$, and the rotor position $\theta$; the output of the commutator is the phase to be excited.

For speed control design purposes, the dynamic model of the VRM can be written as

$$
\begin{gathered}
\frac{d \omega}{d t}=\frac{1}{J}\left\{T_{e}-T_{L}-D \omega\right\}=\alpha, \\
\frac{d \alpha}{d t}=\frac{1}{J}\left\{\sum_{j=1}^{m}\left(\frac{\partial T_{e j}}{\partial i_{j}}\right)\left(\frac{\partial \lambda_{j}}{\partial i_{j}}\right)^{-1}\left(-R_{j} i_{j}-\frac{\partial \lambda_{j}}{\partial \theta} \omega+v_{j}\right)+\omega \sum_{j=1}^{m} \frac{\partial T_{e j}}{\partial \theta}-T_{u}-D \alpha\right\},
\end{gathered}
$$

where $T_{u}=d T_{L} / d t$. 
Let $x=\left(\begin{array}{l}x_{1} \\ x_{2}\end{array}\right)=\left(\begin{array}{c}\omega \\ \alpha\end{array}\right)$. The model of the VRM system can be written in a compact form as

$$
\begin{aligned}
\frac{d x_{1}}{d t} & =x_{2}, \\
\frac{d x_{2}}{d t} & =f+g u, \\
y & =x_{1},
\end{aligned}
$$

where for a 3-phase VRM, $u=v_{j}(j=1$, or 2, or 3) depending on the output of the commutator (i.e., the phase to be excited). The terms $f$ and $g$ are as follows:

$$
\begin{aligned}
f & =\frac{1}{J}\left\{\sum_{j=1}^{m}\left(\frac{\partial T_{e j}}{\partial i_{j}}\right)\left(\frac{\partial \lambda_{j}}{\partial i_{j}}\right)^{-1}\left(-R_{j} i_{j}-\frac{\partial \lambda_{j}}{\partial \theta} \omega\right)+\omega \sum_{j=1}^{m} \frac{\partial T_{e j}}{\partial \theta}-T_{u}-D \alpha\right\} \\
& =f_{n}-\frac{T_{u}}{J} \\
g & =\frac{1}{J}\left(\frac{\partial T_{e j}}{\partial i_{j}}\right)\left(\frac{\partial \lambda_{j}}{\partial i_{j}}\right)^{-1}, \quad i=1,2, \text { or } 3 .
\end{aligned}
$$

Assumption 2.2. The model of the VRM is known as it has been experimentally verified $[26,28]$. Therefore the terms $f_{n}$ and $g$ in the above equations are known. The term $T_{u}$ in $f$ comprises the rate of change of the torque of the incoming phases and the load torque; this term is considered as an uncertain quantity. Thus, the nonlinear term $f$ is not known exactly but can be written as $f=f_{n}+\Delta f$, where $f_{n}$ is the known nominal part of $f$ and $\Delta f$ is the uncertain part of $f$. It is assumed that $\Delta f$ is bounded by a known positive function $\rho$ such that

$$
|\Delta f| \leq \rho
$$

Remark 2.3. The equation $d \theta / d t=\omega$ is not included in model (2.7) of the VRM system because the paper deals with speed control. Obviously, for a given $\omega(t)$, one can easily find $\theta(t)$ such that $\theta(t)=\theta(0)+\int_{0}^{t} \omega(\tau) d \tau$.

Note that at equilibrium, $x_{1 e}=\omega_{\text {ref }}$, and $x_{2 e}=\alpha_{\text {ref }}=0$, where $\omega_{\text {ref }}$ is a constant reference speed command. Define the error $e=\left(\begin{array}{l}e_{1} \\ e_{2}\end{array}\right)$ where $e_{1}$ and $e_{2}$ are such that

$$
\begin{aligned}
& e_{1}=x_{1}-\omega_{\text {ref }}, \\
& e_{2}=x_{2}-\alpha_{\text {ref }}=x_{2} .
\end{aligned}
$$

Using (2.7) and (2.10), the model of the VRM system can be written as

$$
\begin{aligned}
\dot{e}_{1} & =e_{2}, \\
\dot{e}_{2} & =f+g u, \\
y & =x_{1} .
\end{aligned}
$$

The system (2.12) and (2.13) will be used for the design of the control schemes. 


\section{Design of the first robust control scheme for the VRM}

In this section, we propose to use a Corless-/Leitmann-type controller [7] to control the variable reluctance motor.

Define the matrix $A$ and the vector $B$ such that

$$
A=\left[\begin{array}{cc}
0 & 1 \\
-k_{1} & -k_{2}
\end{array}\right], \quad B=\left[\begin{array}{l}
0 \\
1
\end{array}\right],
$$

where the positive scalars $k_{1}$ and $k_{2}$ are chosen such that the polynomial $s^{2}+k_{2} s+k_{1}$ is Hurwitz.

Let $P_{1}$ and $Q_{1}$ be symmetric positive definite matrices such that

$$
A^{T} P_{1}+P_{1} A=-Q_{1}
$$

and let $\epsilon$ be a small positive scalar. In addition, define $\mu_{1}$ such that

$$
\mu_{1}=\rho B^{T} P_{1} e .
$$

Definition 3.1 [12]. The error $e$ is said to be uniformly ultimately bounded if there exist constants $b$ and $c$, and for every $r \in(0, c)$ there is a constant $T=T(r) \geq 0$ such that

$$
\left\|e\left(t_{0}\right)\right\|<r \Longrightarrow\|e(t)\|<b, \quad \forall t>t_{0}+T \text {. }
$$

The following proposition gives the main result of this section.

Proposition 3.2. The control law

$$
u=-\frac{1}{g}\left(f_{n}+k_{1} e_{1}+k_{2} e_{2}\right)+\frac{1}{g} u_{c_{1}}
$$

with

$$
u_{c_{1}}= \begin{cases}-\frac{\mu_{1}}{\left\|\mu_{1}\right\|} \rho & \text { if }\left\|\mu_{1}\right\|>\epsilon, \\ -\frac{\mu_{1}}{\epsilon} \rho & \text { if }\left\|\mu_{1}\right\| \leq \epsilon\end{cases}
$$

when applied to the VRM system (2.12) and (2.13) guarantees the uniform ultimate boundedness of the closed loop system. 
Proof. Using (2.12), (3.1), and (3.4), the closed loop system can be written as

$$
\dot{e}=A e+B u_{c_{1}}+B \Delta f .
$$

Consider the following Lyapunov function candidate $V_{1}$ :

$$
V_{1}=e^{T} P_{1} e
$$

Note that $V_{1}>0$ for $e \neq 0$ and $V_{1}=0$ for $e=0$.

Equation (3.7) implies that $\lambda_{1}\|e\|^{2} \leq V_{1} \leq \lambda_{2}\|e\|^{2}$, where $\lambda_{1}$ is the minimum eigenvalue of $P_{1}$ and $\lambda_{2}$ is the maximum eigenvalue of $P_{1}$.

Taking the derivative of $V_{1}$ with respect to time and using (3.6) and (3.2), it follows that

$$
\begin{aligned}
\dot{V}_{1} & =\dot{e}^{T} P_{1} e+e^{T} P_{1} \dot{e} \\
& =\left(A e+B u_{c_{1}}+B \Delta f\right)^{T} P_{1} e+e^{T} P_{1}\left(A e+B u_{c_{1}}+B \Delta f\right) \\
& =e^{T}\left(A^{T} P_{1}+P_{1} A\right) e+2 e^{T} P_{1} B u_{c_{1}}+2 \Delta f B^{T} P_{1} e \\
& =-e^{T} Q_{1} e+2 e^{T} P_{1} B u_{c_{1}}+2 \Delta f B^{T} P_{1} e .
\end{aligned}
$$

For the case when $\left\|\mu_{1}\right\|>\epsilon$, we have $u_{c_{1}}=\left(-\mu_{1} /\left\|\mu_{1}\right\|\right) \rho$. Hence, the above equation leads to

$$
\begin{aligned}
\dot{V}_{1} & =-e^{T} Q_{1} e-2 \frac{e^{T} P_{1} B \mu_{1}}{\left\|\mu_{1}\right\|} \rho+2 \Delta f B^{T} P_{1} e \\
& =-e^{T} Q_{1} e-2 \frac{\left\|B^{T} P_{1} e\right\|^{2}}{\left\|B^{T} P_{1} e\right\|} \rho+2 \Delta f B^{T} P_{1} e \\
& \leq-e^{T} Q_{1} e-2\left\|B^{T} P_{1} e\right\| \rho+2 \mid \Delta f\|\| B^{T} P_{1} e \| \\
& \leq-e^{T} Q_{1} e \\
& \leq-\lambda_{3}\|e\|^{2},
\end{aligned}
$$

where $\lambda_{3}$ is the minimum eigenvalue of $Q_{1}$.

For the case when $\left\|\mu_{1}\right\| \leq \epsilon$, we have $u_{c_{1}}=\left(-\mu_{1} / \epsilon\right) \rho$. Hence, (3.8) leads to

$$
\begin{aligned}
\dot{V}_{1} & =-e^{T} Q_{1} e-2 \frac{e^{T} P_{1} B \mu_{1}}{\epsilon} \rho+2 \Delta f B^{T} P_{1} e \\
& =-e^{T} Q_{1} e-2 \frac{\left\|B^{T} P_{1} e\right\|^{2}}{\epsilon} \rho^{2}+2 \Delta f B^{T} P_{1} e \\
& \leq-e^{T} Q_{1} e-2 \frac{\left\|B^{T} P_{1} e\right\|^{2}}{\epsilon} \rho^{2}+2 \mid \Delta f\|\| B^{T} P_{1} e \| \\
& \leq-e^{T} Q_{1} e+2\left\|B^{T} P_{1} e\right\| \rho \\
& \leq-e^{T} Q_{1} e+2 \epsilon \\
& \leq-\lambda_{3}\|e\|^{2}+2 \epsilon .
\end{aligned}
$$


Therefore, it can be concluded that for all $t$ and all $x$, we have

$$
\dot{V}_{1} \leq-\lambda_{3}\|e\|^{2}+2 \epsilon .
$$

Let $\kappa=\lambda_{3} / \lambda_{2}$, it follows that

$$
\dot{V}_{1} \leq-\kappa V_{1}+2 \epsilon
$$

Therefore, it can be concluded that $V_{1}$ decreases monotonically along any trajectory of the closed loop system until it reaches the compact set

$$
\Lambda_{s}=\left\{e \mid V_{1} \leq V_{s}=\frac{2 \epsilon}{\kappa}\right\}
$$

Hence the trajectories of the closed loop system of the VRM are uniformly ultimately bounded with respect to the bound $\epsilon$.

\section{Design of the second robust control scheme for the VRM}

The controller proposed in the previous section can only guarantee the uniform ultimate boundedness of the closed loop system. In this section, a second nonlinear state feedback controller is proposed. This controller is similar to the Corless-/Leitmann-type controller in that it works well for a class of nonlinear uncertain systems that have matched uncertainties which are bounded by some known continuous-time functions. However, this control scheme, which is motivated by the work in [20], has the advantage of guaranteeing the exponential stability of the closed loop system.

Let $P_{2}$ and $Q_{2}$ be symmetric positive definite matrices which are solutions to the algebraic Riccati equation

$$
A^{T} P_{2}+P_{2} A-2 P_{2} B B^{T} P_{2}=-Q_{2}
$$

and let

$$
\mu_{2}=\rho B^{T} P_{2} e
$$

and

$$
\vartheta=\frac{\mu_{2}\left\|\mu_{2}\right\|^{2}}{\left\|\mu_{2}\right\|^{3}+\varepsilon^{3} \exp (-3 \beta t)} \rho
$$

with $\varepsilon$ and $\beta$ being positive scalars.

Definition 4.1 [12]. The error $e$ is said to be exponentially stable if

$$
\left\|e\left(t_{0}\right)\right\|<c \Longrightarrow\|e(t)\| \leq \bar{\beta}\left\|e\left(t_{0}\right)\right\| \exp \left(\bar{\gamma}\left(t-t_{0}\right)\right), \quad \forall t \geq t_{0} \geq 0 \text {, with } \bar{\beta}>0, \bar{\gamma}>0 .
$$

The following proposition gives the result of this section. 
Proposition 4.2. The control law

$$
u=-\frac{1}{g}\left(f_{n}+k_{1} e_{1}+k_{2} e_{2}\right)+\frac{1}{g} u_{c_{2}}
$$

with

$$
u_{c_{2}}=-B^{T} P_{2} e-\vartheta
$$

when applied to the VRM system guarantees the exponential stability of the closed loop system.

Proof. The closed loop system can be written as

$$
\dot{e}=A e+B u_{c_{2}}+B \Delta f \text {. }
$$

Using (4.4) and (4.5), it follows that

$$
\begin{aligned}
\dot{e}^{T} P_{2} e & =\left(A e+B\left(-B^{T} P_{2} e-\vartheta\right)+B \Delta f\right)^{T} P_{2} e \\
& =\left(e^{T} A^{T}-e^{T} P_{2} B B^{T}-B^{T} \vartheta+B^{T} \Delta f\right) P_{2} e .
\end{aligned}
$$

Consider the following Lyapunov function candidate $V_{2}$ :

$$
V_{2}=e^{T} P_{2} e
$$

Note that $V_{2}>0$ for $e \neq 0$ and $V_{2}=0$ for $e=0$.

Equation (4.7) implies that $\lambda_{1}^{\prime}\|e\|^{2} \leq V_{2} \leq \lambda_{2}^{\prime}\|e\|^{2}$, where $\lambda_{1}^{\prime}$ is the minimum eigenvalue of $P_{2}$ and $\lambda_{2}^{\prime}$ is the maximum eigenvalue of $P_{2}$.

Taking the derivative of $V_{2}$ with respect to time and using (4.6), (3.14), and (4.2), it follows that

$$
\begin{aligned}
\dot{V}_{2} & =\dot{e}^{T} P_{2} e+e^{T} P_{2} \dot{e} \\
& =e^{T}\left(A^{T} P_{2}+P_{2} A-2 P_{2} B B^{T} P_{2}\right) e-2 e^{T} P_{2} B \vartheta+2 e^{T} P_{2} B \Delta f \\
& =-e^{T} Q_{2} e-2 e^{T} P_{2} B \vartheta+2 e^{T} P_{2} B \Delta f \\
& =-e^{T} Q_{2} e-\frac{2 e^{T} P_{2} B \mu_{2}\left\|\mu_{2}\right\|^{2}}{\left\|\mu_{2}\right\|^{3}+\varepsilon^{3} \exp (-3 \beta t)} \rho+2 e^{T} P_{2} B \Delta f \\
& \leq-e^{T} Q_{2} e-\frac{2\left\|B^{T} P_{2} e\right\|^{4} \rho^{4}}{\left\|B^{T} P_{2} e\right\|^{3} \rho^{3}+\varepsilon^{3} \exp (-3 \beta t)}+2\left\|B^{T} P_{2} e\right\| \rho \\
& \leq-e^{T} Q_{2} e+\frac{2\left\|B^{T} P_{2} e\right\| \rho \varepsilon^{3} \exp (-3 \beta t)}{\left\|B^{T} P_{2} e\right\|^{3} \rho^{3}+\varepsilon^{3} \exp (-3 \beta t)} \\
& \leq-e^{T} Q_{2} e+2 \varepsilon \exp (-\beta t) \\
& \leq-\lambda_{3}^{\prime}\|e\|^{2}+2 \varepsilon \exp (-\beta t),
\end{aligned}
$$


Table 5.1. Parameters of the VRM.

\begin{tabular}{l|c}
\hline Parameter & Value \\
\hline Output power & $20 \mathrm{~kW}$ \\
Rated speed & $492 \mathrm{rad} / \mathrm{s}$ \\
Number of phases $(m)$ & 3 \\
Number of stator poles & 6 \\
Number of rotor poles & 4 \\
Aligned phase inductance $\left(L_{a}\right)$ & $19.0 \mathrm{mH}$ \\
Unaligned phase inductance $\left(L_{u}\right)$ & $0.67 \mathrm{mH}$ \\
Rotor inertia $(J)$ & $0.02 \mathrm{Nm} \mathrm{s}$ \\
Damping factor $(D)$ & $0.3301 \times 10^{-3} \mathrm{Nm} \mathrm{s}$ \\
Phase resistance $(R)$ & $0.069 \Omega$ \\
DC voltage supply & $230 \mathrm{~V}$ \\
\hline
\end{tabular}

where the fact that $0 \leq a b^{3} /\left(a^{3}+b^{3}\right) \leq b$ for $a, b \geq 0$ and $a^{3}+b^{3} \neq 0$ was used; and $\lambda_{3}^{\prime}$ is the minimum eigenvalue of $Q_{2}$.

Let $\kappa^{\prime}=\lambda_{3}^{\prime} / \lambda_{2}^{\prime}$, it follows that

$$
\dot{V}_{2} \leq-\kappa^{\prime} V_{2}+2 \varepsilon \exp (-\beta t)
$$

Thus, it can be concluded that the error $e(t)$ is globally exponentially stable. Moreover, the convergence rate of the errors is such that

$$
\|e(t)\| \leq \begin{cases}{\left[\frac{\lambda_{2}^{\prime}}{\lambda_{1}^{\prime}}\|e(0)\|^{2} \exp \left(-\kappa^{\prime} t\right)+\frac{2 \varepsilon}{\lambda_{1}^{\prime}} t \exp \left(-\kappa^{\prime} t\right)\right]^{1 / 2}} & \text { if } \beta=\kappa^{\prime}, \\ {\left[\frac{\lambda_{2}^{\prime}}{\lambda_{1}^{\prime}}\|e(0)\|^{2} \exp \left(-\kappa^{\prime} t\right)+\frac{2 \varepsilon}{\lambda_{1}^{\prime}\left(\kappa^{\prime}-\beta\right)}\left(\exp (-\beta t)-\exp \left(-\kappa^{\prime} t\right)\right)\right]^{1 / 2}} & \text { if } \beta \neq \kappa^{\prime} .\end{cases}
$$

\section{Simulation results of the proposed controllers}

The VRM system is simulated using the Matlab software. The VRM model discussed in Section 2 is adopted; the model takes magnetic saturation into account.

The parameters of the motor are given in Table 5.1.

The excitation angles $\left(\theta_{\text {on }}\right.$ and $\left.\theta_{\text {off }}\right)$ are kept fixed throughout the simulation studies at $45^{\circ}$ and $79^{\circ}$, respectively, (where $0^{\circ}$ and $90^{\circ}$ correspond to aligned and unaligned positions). Only one phase is allowed to be excited at one time.

Simulations are performed when the proposed controllers are applied to the VRM system. The results are presented in the following subsections.

5.1. Performance of the VRM system when the first controller is used. The control scheme given by (3.4) and (3.5) is applied to the VRM system. The desired speed is $100 \mathrm{rad} / \mathrm{s}$ for $0 \leq t<0.1$ seconds, and it is $200 \mathrm{rad} / \mathrm{s}$ for $0.1 \leq t \leq 0.2 \mathrm{~seconds}$. The load 


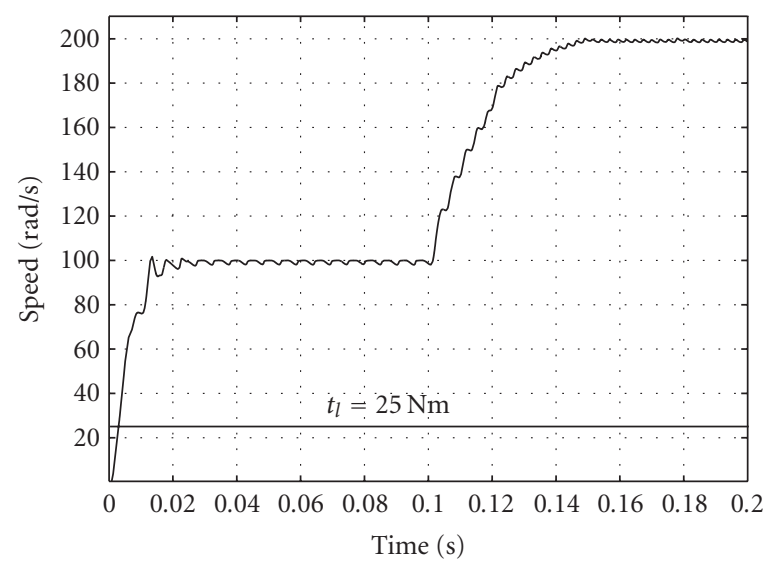

Figure 5.1. Speed response of the VRM when the first controller is used.

torque is taken to be $25 \mathrm{Nm}$. Figure 5.1 shows the speed response of the motor. It can be seen from the figure that the motor speed converges to the desired speeds. It should be mentioned that the ripples in the speed response are due to the sequential switching between the phases and they are not caused by the controller.

5.2. Performance of the VRM system when the second controller is used. The control law described by (4.3) and (4.4) is applied to the VRM system. Figure 5.7 shows the speed response of the motor when it is commanded to accelerate from rest to a reference speed of $100 \mathrm{rad} / \mathrm{s}$ then to $200 \mathrm{rad} / \mathrm{s}$, with a load torque of $25 \mathrm{Nm}$. It can be seen that the motor speed converges to the desired speeds. The ripples in the speed response are due to the motor operational characteristics and limits of the electronic commutator; the ripples are not due to the proposed controller.

Remark 5.1. The VRM used for simulation studies is a 3-phase 6/4 motor. The low number of poles will have a negative impact on the produced torque of the motor. As a result, the speed will be affected and hence the response of the speed will have more ripples.

5.3. Robustness of the proposed control schemes. Simulation studies are undertaken to test the robustness of the proposed controllers to variations in the parameters. Changes in the phase resistance $R$, the rotor inertia $J$, the damping factor $D$, and the $a_{1 j}, a_{2 j}$, and $a_{3 j}(j=1,2, \ldots, m)$ coefficients (which are used to model the phase flux-linkage) are investigated. The simulations are carried out by step changing one parameter at a time while keeping the other parameters unchanged. The step change occurs at time $t=0.1$ seconds and at time $t=0.15$ seconds. The motor is commanded to accelerate from rest to a reference speed of $200 \mathrm{rad} / \mathrm{s}$ with a load torque of $25 \mathrm{Nm}$.

Figures 5.2-5.5 and 5.8-5.11 show the motor responses when there are changes in the parameters of the VRM system. Figure 5.2 (first controller) and Figure 5.8 (second controller) show the responses of the motor when the phase resistance is increased to $200 \%$ 


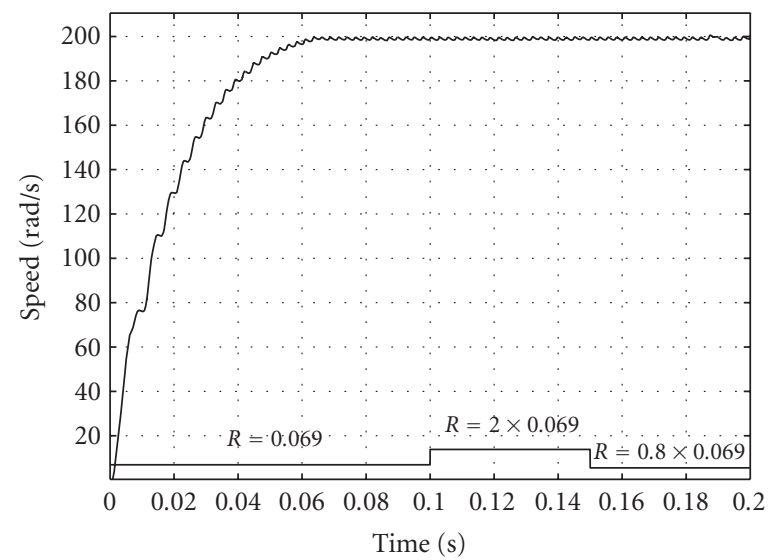

Figure 5.2. Speed response of the VRM when the first controller is used with changes in $R$.

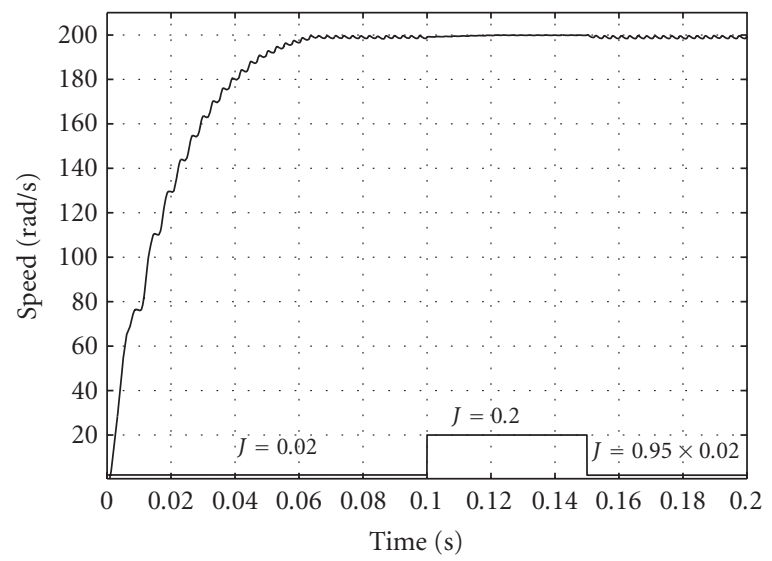

Figure 5.3. Speed response of the VRM when the first controller is used with changes in $J$.

of its original value and then decreased to $80 \%$ of its original value. Figure 5.3 (first controller) and Figure 5.9 (second controller) show the responses of the motor when the rotor inertia is varied by up to 10 times its original value. Figure 5.4 (first controller) and Figure 5.10 (second controller) show the responses of the motor when the damping factor is varied by up to 10 times its original value. Figure 5.5 (first controller) and Figure 5.11 (second controller) show the responses of the motor when the $a_{1 j}, a_{2 j}$, and $a_{3 j}(j=1,2, \ldots, m)$ coefficients are increased to $110 \%$ of their original values and then decreased to $90 \%$ of their original values; the change in the coefficients is only $10 \%$ because these coefficients are usually known quite accurately from experimental studies. Hence, it can be concluded from the simulation results that the proposed controllers are robust to changes in the parameters of the system. 


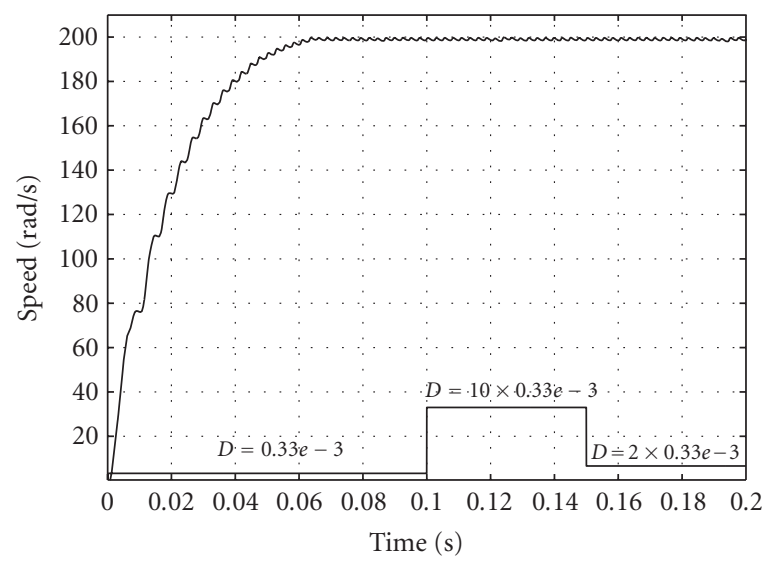

Figure 5.4. Speed response of the VRM when the first controller is used with changes in $D$.

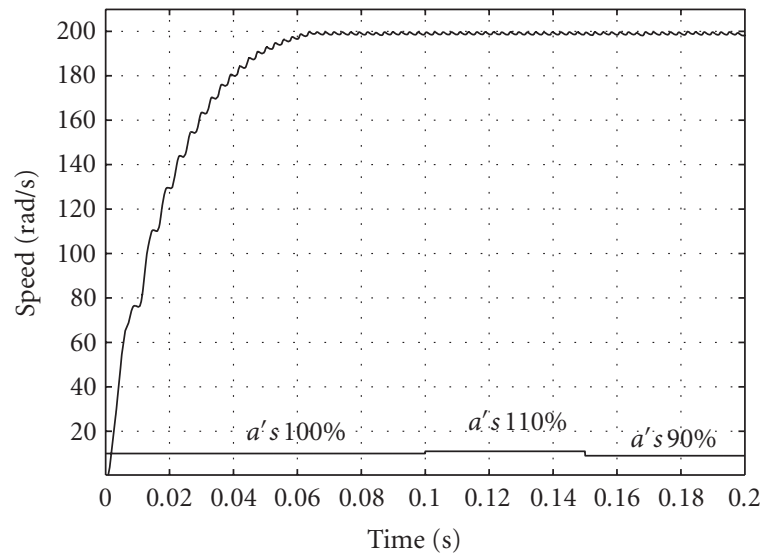

Figure 5.5. Speed response of the VRM when the first controller is used with changes in the $a_{i j}^{\prime} s$ coefficients.

It is desirable for high-performance applications that the proposed control schemes be robust to variations in the load torque. Simulation studies are carried out to demonstrate the robustness of the proposed controllers to changes in the load torque. The motor is commanded to accelerate from rest to $200 \mathrm{rad} / \mathrm{s}$. Figure 5.6 (first controller) and Figure 5.12 (second controller) show the motor responses when the load torque changes from $25 \mathrm{Nm}$ to $50 \mathrm{Nm}$ and back to $25 \mathrm{Nm}$. It can be seen from these two figures that the motor responses have a dip in speed when the load is suddenly changed, but both controllers are able to keep the motor speed close to the desired speed. Therefore, it can be concluded that the proposed controllers are robust to changes in the load. 


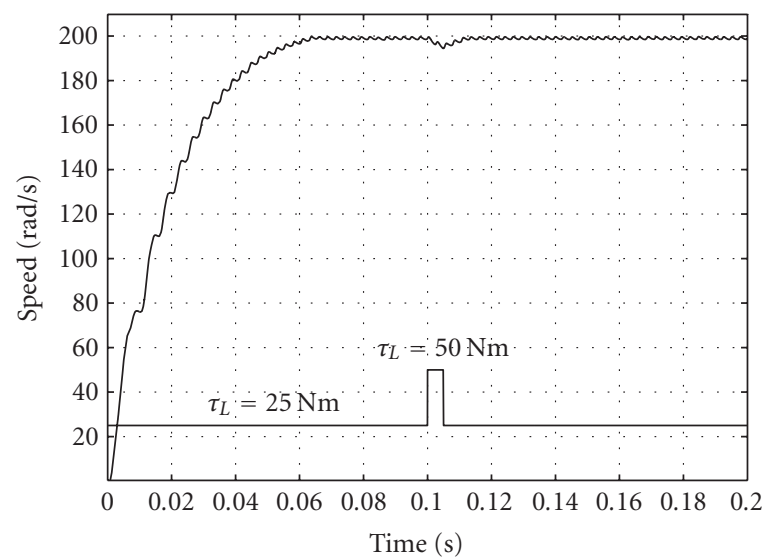

Figure 5.6. Speed response of the VRM when the first controller is used with changes in the load torque.

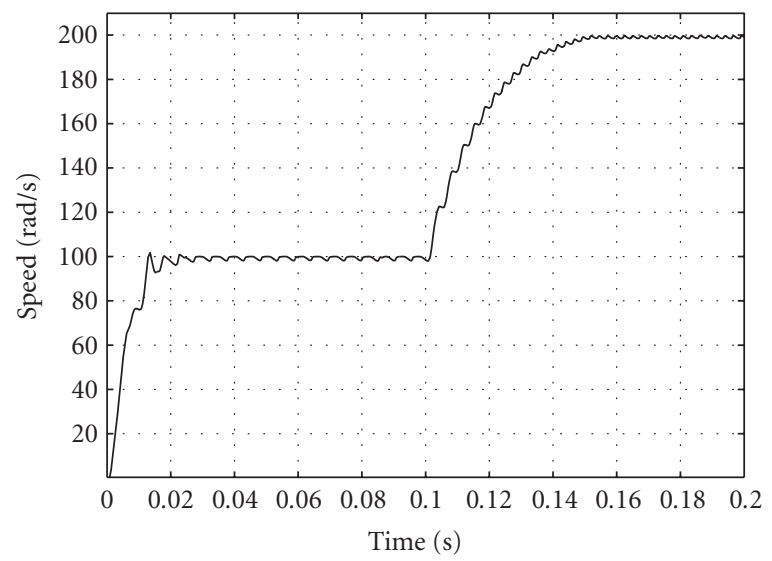

Figure 5.7. Speed response of the VRM when the second controller is used.

\subsection{Comparison of the proposed control schemes with a PI controller and a feedback} linearization controller. The performance of the closed loop system is compared to the performance of the system when (1) a proportional plus integral (PI) controller is used, and (2) a feedback linearization controller is used. The choice of the PI controller is motivated by the fact that the PI controller is usually used in industrial VRMs. The choice of the feedback linearization controller is due to the simplicity of the design of this type of controllers.

The equation of the PI controller is as follows:

$$
u=K_{p}\left(\omega-\omega_{\text {ref }}\right)+K_{I} \int\left(\omega-\omega_{\text {ref }}\right) d t=K_{p} e_{1}+K_{I} \int e_{1} d t
$$

The gains $K_{p}$ and $K_{I}$ are tuned using the trial and error method. 


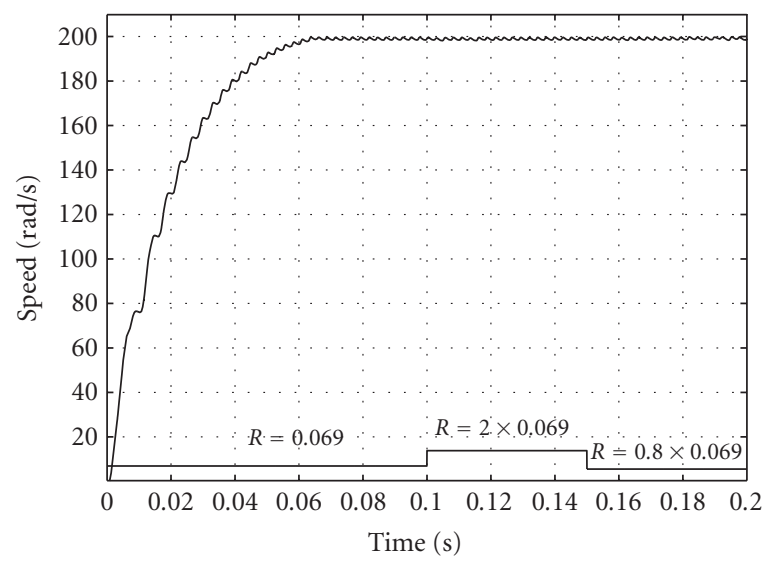

Figure 5.8. Speed response of the VRM when the second controller is used with changes in $R$.

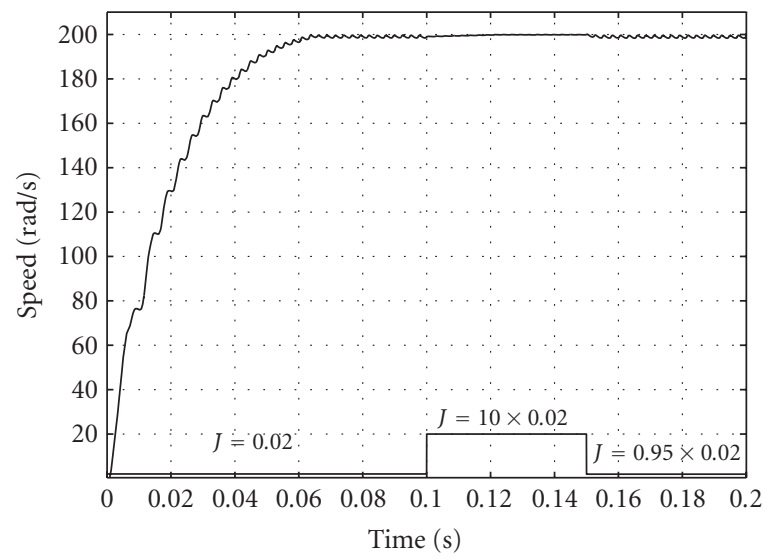

Figure 5.9. Speed response of the VRM when the second controller is used with changes in $J$.

The control scheme given by (5.1) is applied to the VRM system. The desired speed is $100 \mathrm{rad} / \mathrm{s}$ for $0 \leq t<0.1$ seconds, and it is $200 \mathrm{rad} / \mathrm{s}$ for $0.1 \leq t \leq 0.2 \mathrm{~seconds}$; the load torque is taken to be $25 \mathrm{Nm}$. Figure 5.13 shows the speed response of the motor. It can be seen from the figure that the motor speed converges to the desired speeds.

Recall that the model of the VRM system can be written as

$$
\begin{aligned}
\dot{e}_{1} & =e_{2}, \\
\dot{e}_{2} & =f+g u, \\
y & =x_{1} .
\end{aligned}
$$




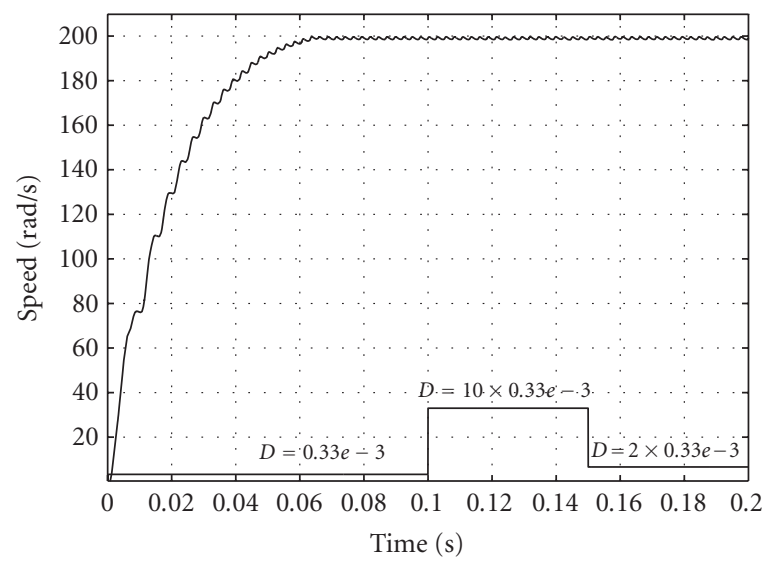

Figure 5.10. Speed response of the VRM when the second controller is used with changes in $D$.

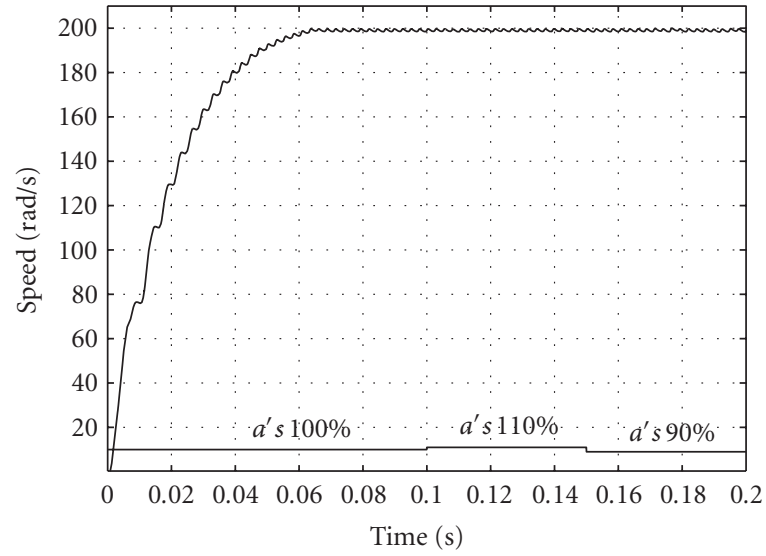

Figure 5.11. Speed response of the VRM when the second controller is used with changes in the $a_{i j}^{\prime} s$ coefficients.

A feedback linearization controller for the above system can be written as

$$
u=-\frac{1}{g}\left(f+k_{1} e_{1}+k_{2} e_{2}\right)
$$

where $k_{1}$ and $k_{2}$ are properly designed gains. The value of $f$ is taken to be the nominal value.

The control scheme given by (5.3) is applied to the VRM system. Figure 5.14 shows the speed response of the motor. It can be seen from the figure that the motor speed converges to the desired speeds.

Figures 5.13 and 5.14 show the responses of the VRM system when the PI controller, the feedback linearization controller, and the two proposed controllers are used. It can 


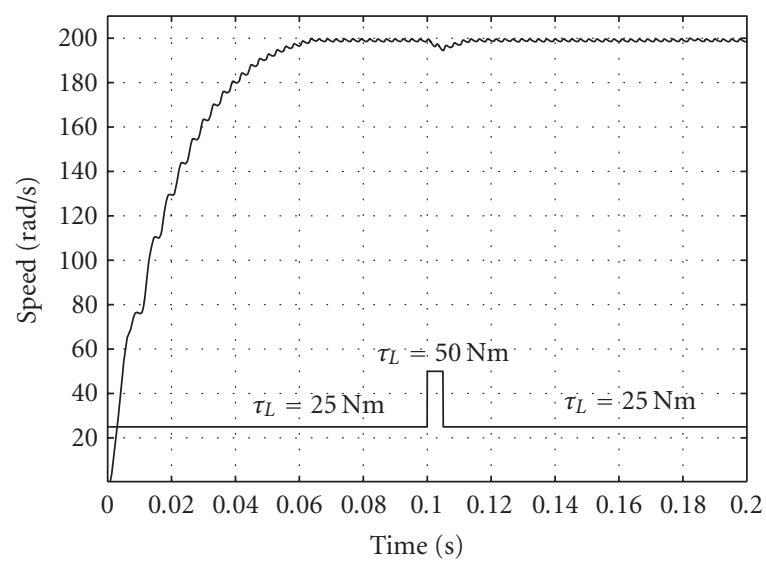

Figure 5.12. Speed response of the VRM when the second controller is used with changes in the load torque.

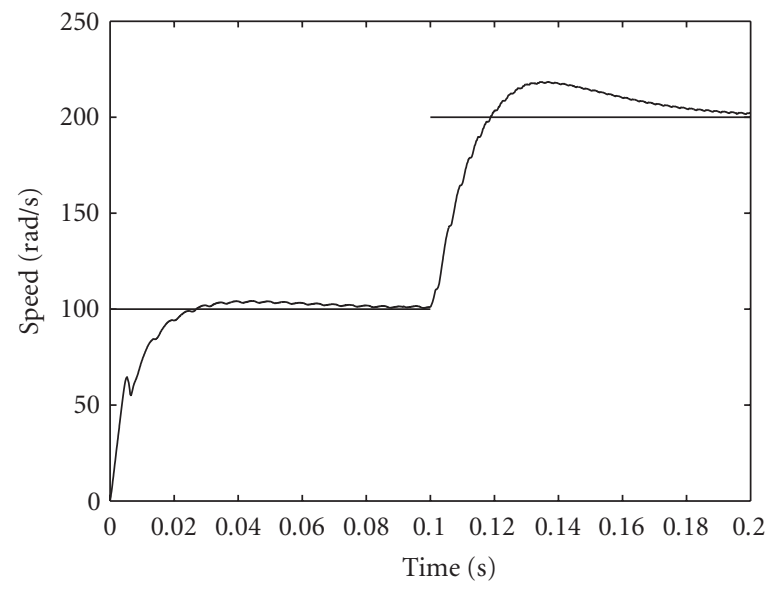

Figure 5.13. Speed response of the VRM when the PI controller is used.

be seen that the four controllers force the speed of the motor to converge to the desired speeds. However, it can be seen from the figures that the proposed controllers gave better results than the PI controller or the feedback linearization controller. This is an expected result as the PI controller is a simple controller to design and to implement. The design of the feedback linearization controller did not take the uncertainties of the VRM system into account and hence it did not perform as well as the two proposed controllers. In addition, the second controller gave slightly better results than the first controller (as can be seen from Figure 5.14) since the first controller guarantees the uniform ultimate boundedness of the system and the second controller guarantees the exponential stability of the system. 
212 Robust controllers for variable reluctance motors

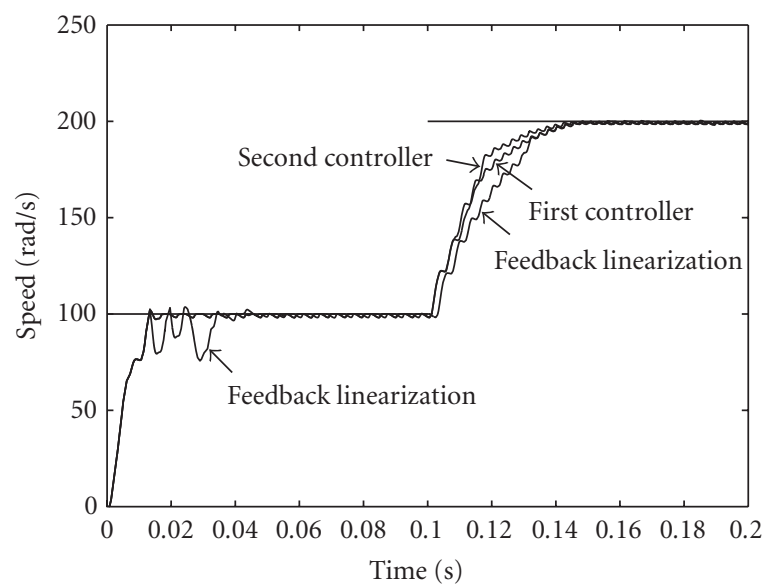

Figure 5.14. Speed response of the VRM when the feedback linearization controller, the first controller, and the second controller are used.

\section{Conclusion}

In this paper, two control schemes are designed for the speed control of variable reluctance motors. The first proposed controller guarantees the uniform ultimate boundedness of the closed loop system; the second controller guarantees the exponential stability of the closed loop system. A highly nonlinear model is adopted for the design of the controllers, this model takes magnetic saturation into account. The proposed controllers are based on varying the terminal voltage of the motor using a DC-DC chopper. The inputs to the controllers are the phase currents, the rotor position, and the speed of the motor. The performances of the controllers are illustrated through simulations. The results indicate that the proposed control schemes are able to bring the motor speed to the desired speed. Moreover, the simulation results show the robustness of the proposed controllers to changes in the parameters of a motor and to changes in the load. Future work will address the implementation of the proposed control schemes using a DSP-based digital controller board.

\section{Acknowledgment}

This research was supported by Kuwait University under research Grant no. EE 03/02.

\section{References}

[1] M. T. Alrifai, J. H. Chow, and D. A. Torrey, Backstepping nonlinear speed controller for switchedreluctance motors, Elec. Power App. 150 (2003), no. 2, 193-200.

[2] P. R. Bevington, Data Reduction and Error Analysis for the Physical Sciences, McGraw-Hill, New York, 1969.

[3] S. Bolognani and M. Zigliotto, Fuzzy logic control of a switched reluctance motor drive, IEEE Trans. Ind. Applicat. 32 (1996), no. 5, 1063-1068.

[4] S. A. Bortoff, R. R. Kohan, and R. Milman, Adaptive control of variable reluctance motors: $a$ spline function approach, IEEE Trans. Ind. Electron. 45 (1998), no. 3, 433-444. 
[5] E. Capecchi, P. Gugliehni, M. Pastorelli, and A. Vagati, Position-sensorless control of the transverse-laminated synchronous reluctance motor, IEEE Trans. Ind. Applicat. 37 (2001), no. $6,1768-1776$.

[6] T.-S. Chuang and C. Pollock, Robust speed control of a switched reluctance vector drive using variable structure approach, IEEE Trans. Ind. Electron. 44 (1997), no. 6, 800-808.

[7] M. J. Corless and G. Leitmann, Continuous state feedback guaranteeing uniform ultimate boundedness for uncertain dynamic systems, IEEE Trans. Automat. Contr. 26 (1981), no. 5, 11391144.

[8] W. D. Harris and J. H. Lang, A simple motion estimator for variable-reluctance motors, IEEE Trans. Ind. Applicat. 26 (1990), no. 2, 237-243.

[9] K. I. Hwu and C. M. Liaw, Quantitative speed control for SRM drive using fuzzy adapted inverse model, IEEE Trans. Aerosp. Electron. Syst. 38 (2002), no. 3, 955-968.

[10] F. Ismail, S. Wahsh, A. Mohamed, and H. Elsimary, Optimal control of variable reluctance motor by neural network, Proceedings of the IEEE International Symposium on Industrial Electronics (ISIE '93) (Budapest), 1993, pp. 301-304.

[11] F. Ismail, S. Wahsh, and A. Z. Mohamed, Fuzzy-neuro based optimal control of variable reluctance motor, Proc. 4th IEEE Conference on Control Applications (New York), 1995, pp. 768773.

[12] H. K. Khalil, Nonlinear Systems, Macmillan Publishing, New York, 1992.

[13] C.-H. Kim and I.-J. Ha, A new approach to feedback-linearizing control of variable reluctance motors for direct-drive applications, IEEE Trans. Contr. Syst. Technol. 4 (1996), no. 4, 348 362.

[14] C. G. Lo Bianco, A. Tonielli, and F. Filicori, A prototype controller for variable reluctance motors, IEEE Trans. Ind. Electron. 43 (1996), no. 1, 207-216.

[15] P. Materu and R. Krishnan, Estimation of switched reluctance motor losses, Proc. IEEE Conference Record of the Industry Applications Society Annual Meeting (Pennsylvania), vol. 1, 1988, pp. 79-90.

[16] H. Melkote, F. Khorrami, S. Jain, and M. S. Mattice, Robust adaptive control of variable reluctance stepper motors, IEEE Trans. Contr. Syst. Technol. 7 (1999), no. 2, 212-221.

[17] A. M. Michaelides and C. Pollock, Modelling and design of switched reluctance motors with two phases simultaneously excited, Elec. Power App. 143 (1996), no. 5, 361-370.

[18] T. J. E. Miller, Brushless Permanent-Magnet and Reluctance Motor Drives, Clarendon Press, Oxford, 1989.

[19] R. Milman and S. A. Bortoff, Observer-based adaptive control of a variable reluctance motor: experimental results, IEEE Trans. Contr. Syst. Technol. 7 (1999), no. 5, 613-621.

[20] S. K. Nguang and M. Fu, Global quadratic stabilization of a class of nonlinear systems, Internat. J. Robust Nonlinear Control 8 (1998), no. 6, 483-497.

[21] S. K. Panda, K. Y. Chong, and K. S. Lock, Indirect rotor position sensing for variable reluctance motors, Proc. IEEE Conference Record of the Industry Applications Society Annual Meeting (Colorado), vol. 1, 1994, pp. 644-648.

[22] S. K. Panda and P. K. Dash, Application of nonlinear control to switched reluctance motors: a feedback linearisation approach, Elec. Power App. 143 (1996), no. 5, 371-379.

[23] C. Pollock and A. M. Michaelides, Switched reluctance drives: a comparative evaluation, Power Engineering Journal 9 (1995), no. 6, 257-266.

[24] M. M. Rayan, M. M. Mansour, M. A. El-Sayad, and M. S. Morsy, Implementation and testing of a digital controller for variable reluctance motor, Proc. IEEE 14th Annual Applied Power Electronics Conference and Exposition (APEC'99) (Texas), vol. 1, 1999, pp. 430-433.

[25] C. Rossi, A. Tonielli, C. G. Lo Bianco, and F. Filicori, Robust control of a variable reluctance motor, Proc. IEEE/RSJ International Workshop on Intelligent Robots and Systems. Intelligence for Mechanical Systems (IROS '91) (Osaka), vol. 1, 1991, pp. 337-343. 


\section{Robust controllers for variable reluctance motors}

[26] D. A. Torrey, An experimentally verified variable-reluctance machine model implemented in the Saber circuit simulator, Electric Machines and Power Systems 24 (1996), 199-210.

[27] D. A. Torrey and J. H. Lang, Modelling a nonlinear variable-reluctance motor drive, Elec. Power App. 137 (1990), no. 5, 314-326.

[28] D. A. Torrey, X.-M. Niu, and E. J. Unkauf, Analytical modelling of variable-reluctance machine magnetisation characteristics, Elec. Power App. 142 (1995), no. 1, 14-22.

[29] I.-W. Yang and Y.-S. Kim, Rotor speed and position sensorless control of a switched reluctance motor using the binary observer, Elec. Power App. 147 (2000), no. 3, 220-226.

[30] L.-C. R. Zai, D. G. Manzer, and C.-Y. D. Wong, High-speed control of variable reluctance motors with reduced torque ripple, Proc. 7th Annual Applied Power Electronics Conference and Exposition (APEC '92) (Massachusetts), 1992, pp. 107-113.

Mohamed Zribi: Department of Electrical Engineering, College of Engineering \& Petroleum, Kuwait University, P. O. Box 5969, Safat 13060, Kuwait

E-mail address: mzribi@eng.kuniv.edu.kw

Muthana T. Alrifai: Department of Electrical Engineering, College of Engineering \& Petroleum, Kuwait University, P. O. Box 5969, Safat 13060, Kuwait

E-mail address: alrifm@eng.kuniv.edu.kw 


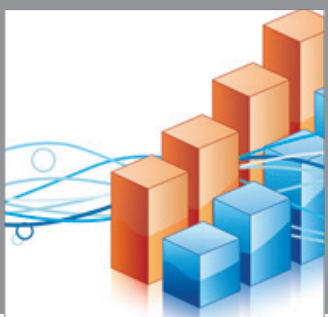

Advances in

Operations Research

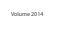

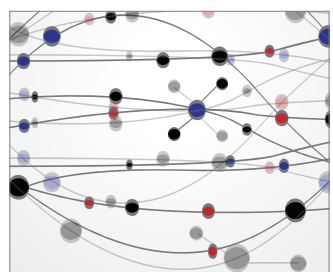

\section{The Scientific} World Journal
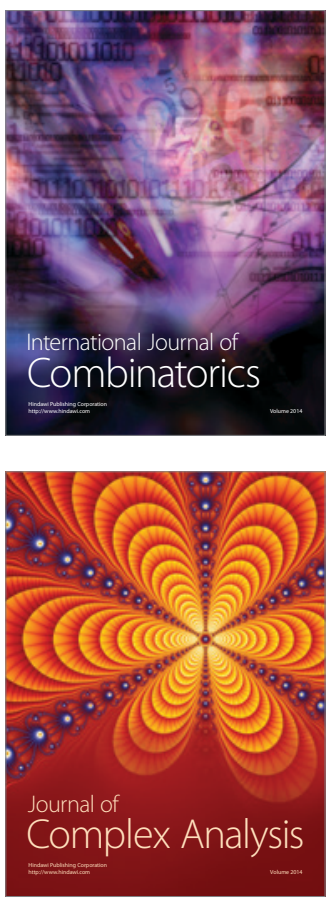

International Journal of

Mathematics and

Mathematical

Sciences
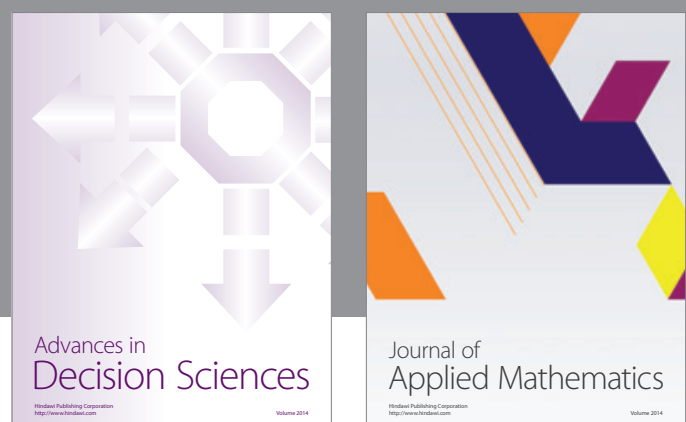

Journal of

Applied Mathematics
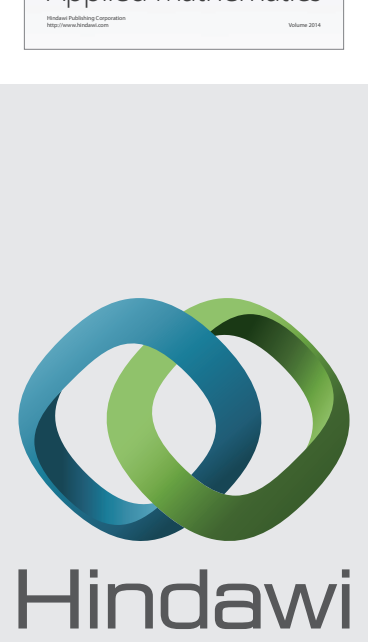

Submit your manuscripts at http://www.hindawi.com
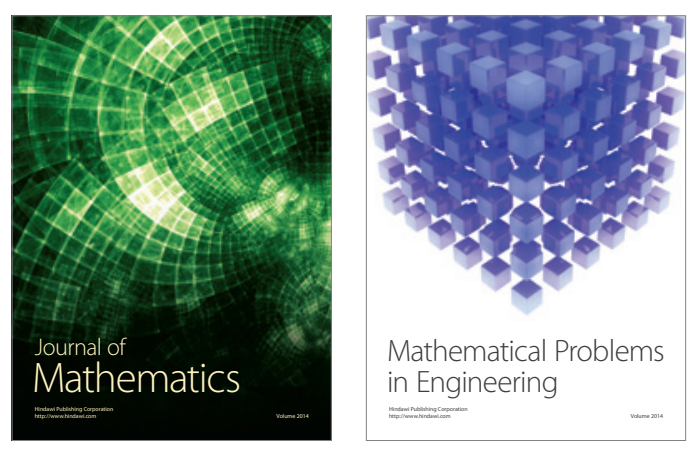

Mathematical Problems in Engineering
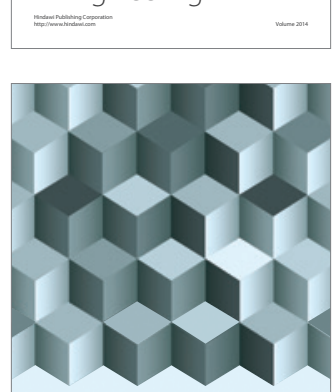

Journal of

Function Spaces
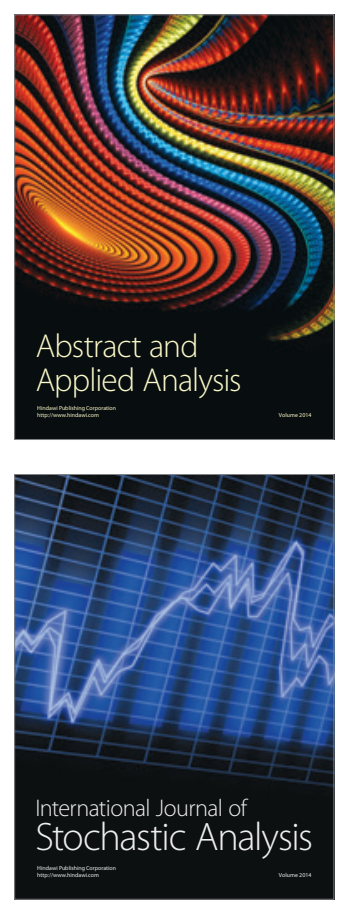

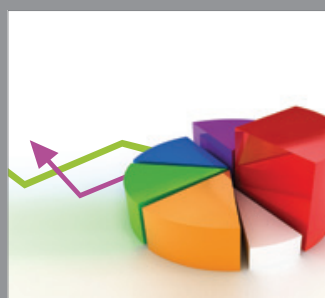

ournal of

Probability and Statistics

Promensencen
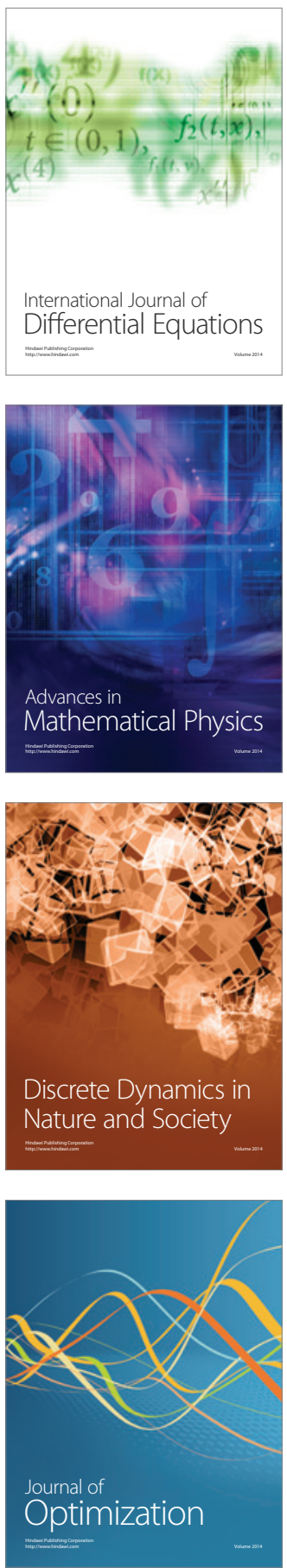